\title{
Disparities in Mental Well-being between Non-Minority and Sexual Minority Male Youth in Bangkok, Thailand: Quantitative Findings from a Mixed Method Study
}

\author{
Sakol Sopitarchasak ${ }^{1}$, Masahiro Kihara ${ }^{2}$, Kyaw Min Soe ${ }^{3}$ \& Masako Ono-Kihara²
}

This paper investigates whether there are differences in mental well-being between non-minority and sexual minority adolescents. We also explore the experiences of victimization among sexual minority adolescents, compared to their non-minority peers. While the study used mixed methods, with an initial qualitative phase and a subsequent quantitative phase, this paper focuses on the quantitative findings. Male students from five secondary schools $(n=1,250)$ in Bangkok were asked to answer an online questionnaire. Among all participants, $81.8 \%$ identified themselves as non-minority and $12.5 \%$ as sexual minority with $5.7 \%$ missing or unidentifiable responses. The results indicated a higher risk of depression for sexual minority participants than for non-minority participants (odds ratio: 1.85). Sexual minority participants were also more likely than their non-minority peers to have considered $(23.2 \%$ vs. $9.8 \%)$ or attempted $(10.3 \%$ vs. $2.9 \%)$ suicide, and to have been victimized and/or experienced sexual coercion during the past semester. The findings conform to results from previous studies worldwide. Although a causal relationship cannot be inferred from this study, the disparity in mental well-being can be due to the victimization that sexual minority adolescents experience more frequently than their non-minority counterparts.

Keywords: Adolescents; Depression; Suicide; Victimization; Sexuality

Globally, many studies have reported higher rates of psychological distress, self-harm, suicide, suicide attempts and suicidal ideation among sexual minority populations (Clements-Nolle, Marx \& Katz, 2006; Diamant \& Wold, 2003; DiStefano, 2008; Fergusson, Horwood, Ridder \& Beautrais, 2005; Fitzpatrick, Euton, Jones \& Schmidt, 2005; King et al., 2013; Warner et al., 2004). This association is further linked with social discrimination and oppression targeted towards these groups (Diaz, Ayala \& Bein, 2001; Warner et al., 2004).

Higher rates of suicidality and compromised mental well-being were also reported among sexual minority adolescents (Consolacion, Russell \& Sue, 2004; Galliher, Rostosky \& Hughes, 2004; Garofalo, Wolf, Wissow, Woods \& Goodman, 1999; Gary Remafedi, Farrow \& Deisher, 1991; Russell \& Joyner, 2001). According to a meta-analytic study by Marshal et al. (2001), significantly higher rates of suicidality (odds ratio $=2.92$ ) and a higher tendency for depression (standardized mean difference $=0.33$ ) among sexual minority youths than non-minority youths were reported (Marshal et al., 2011).

Meyer (2003) has proposed the minority stress model, where minority status is linked to mental outcomes through distal minority stressors (e.g. discrimination and violence) and proximal minority stressors (e.g. expectations of rejection and concealment). Empirically, compromises in mental health and higher rates of suicidality among sexual minority groups were found to be associated with discrimination and harassment related to their sexual orientation (Birkett, Espelage \& Koenig, 2009). It also has been shown by mediation analyses

\footnotetext{
1 Thai Health Promotion Foundation, Bangkok, Thailand. Email: sakol@thaihealth.or.th

2 Kyoto University, Kyoto, Japan.

3 Mahidol University, Bangkok, Thailand.
} 
that discrimination and victimization account for the association between sexual orientation and depressive symptomatology (Almeida, Johnson, Corliss, Molnar \& Azrael, 2009; Burton, Marshal, Chisolm, Sucato \& Friedman, 2013; Williams, Connolly, Pepler \& Craig, 2005). The situation highlights the concern for sexual minority adolescents' well-being, especially given that adolescence is a critical period; mental disorders experienced during this phase can continue to have an impact in adulthood (Kessler et al., 2005; McEwan, Waddell, Barker \& Kirby, 2007).

In Thailand, van Griensven et al. (2004) investigated adolescents' well-being in relation to their sexual orientation, although their study focused heavily on adolescents' sexual health. Another study conducted among secondary school students in Thailand found that students who were bullied tended to do worse in school, were more likely to be depressed and to have attempted suicide (Mahidol University, Plan International \& UNESCO, 2014). The study also found that the compromised well-being worsened when bullying occurred because perpetrators thought victims were LGBT as compared to being bullied for other reasons (Mahidol University et al., 2014). Other studies in recent years have also affirmed the worsened mental well-being among sexual minorities in Thailand (Boonkerd \& Rungreangkulkij, 2014; Yadegarfard, Meinhold-Bergmann \& Ho, 2014).

This study investigates the issue of disparity in mental well-being status between non-minority and sexual minority adolescents in Thailand. It also examines experiences of victimization among sexual minority adolescents, not only by peers but by parents and school staff. In this way the study provides a more holistic picture of the situation that sexual minority adolescents encounter.

\section{Methods}

The study used mixed methods, with an initial qualitative phase and a subsequent quantitative phase. The initial qualitative study was conducted to obtain insights for constructing the questionnaire to be used in the following quantitative study. A detailed description of the methodology used in the qualitative phase can be found in a separate published article by Sopitarchasak et al. (2015).

Target population and inclusion criteria. The target population for the study is male adolescents attending secondary schools in Bangkok, Thailand. According to the Ministry of Education, there were 152,439 secondary school students (grades 10 to 12) in Bangkok in 2015. Among those, 64,594 were male students, comprising approximately $11.8 \%$ of male secondary school students in the whole country (Ministry of Education, 2016). The inclusion criteria for participants in the quantitative phase included (1) having male sex at birth; (2) currently attending secondary school in Bangkok; and (3) able to read and write Thai fluently.

Sample size and sampling method. A sample size of 1,000 participants was estimated to be adequate for this study, calculated as follows. We hypothesized that sexual minority adolescents' mean score on the Center for Epidemiologic Studies-Depression scale (CES-D) would be higher than that of non-minority adolescents. From a study utilizing a Thai version of the CES-D, the mean CES-D score for the general population can be approximated at 15.4, with a standard deviation of 6.7 (Trangkasombat, Larpboonsarp \& Havanond, 1997). According to a meta-analysis of ten studies in the USA and one study in Thailand that 
examined depression among heterosexual and sexual minority youth, the estimate for the overall standardized difference of the mean of the CES-D score between non-minority and sexual minority adolescents was 0.33 (Marshal et al., 2011). Assuming the same results, we predict the CES-D mean score for the sexual minority adolescents to be approximately 17.6. With a significance level set at 5\% (two-sided), power at $80 \%$, and assuming the approximate proportion of sexual minority students to be around $10 \%$ among the student population ${ }^{4}$, the calculated sample size for the non-minority minority group and the sexual group is 728 and 81 respectively. Thus total minimum sample size obtained by combining the two groups is 809 . Considering the possibility of non-responses and invalid answers, it was deemed that a sample size of at least 1,000 participants was required for this study (Chow, Wang \& Shao, 2007).

Considering the time limits for the study, participating schools were chosen partly by convenience sampling and partly by purposive sampling. The first three schools (Schools a, $\mathrm{b}$ and $\mathrm{c}$ ) were chosen following convenience considerations because they had previously participated in another research project conducted by project staff. The other two schools (Schools $\mathrm{d}$ and e) were selected purposively, by sorting a list of schools in Bangkok according to the number of male secondary school students. The two schools with the highest number of male secondary school students among boys-only and among co-educational schools were then contacted to ask for their permission to participate in the study (four schools in total). Among those, both co-educational schools refused to participate. Teachers responsible for coordinating this project in the two (boys-only) participating schools were then asked to inform all male students $\left(10^{\text {th }}-12^{\text {th }}\right.$ grade $)$ about the study and ask for their assent to participate. The number of participants and response rate is shown in Table 1 . Only students in the $10^{\text {th }}$ grade in school $\mathrm{c}$ and $12^{\text {th }}$ grade in school e were allowed by the schools to participate, due to limitations in their class schedules. This is considered to not influence the results of this study since all students in the entire allowed grades were allowed to participate in the study.

Table 1: Number of Participants and Response Rates

\begin{tabular}{crrrr}
\hline School & $\begin{array}{r}\text { Male secondary } \\
\text { school students }\end{array}$ & Allowed target & Participants & Response rate \\
\hline $\mathrm{a}$ & 110 & 110 & 84 & $76.4 \%$ \\
$\mathrm{~b}$ & 111 & 111 & 72 & $64.9 \%$ \\
$\mathrm{C}^{*}$ & 512 & 157 & 131 & $83.4 \%$ \\
$\mathrm{~d}$ & 1,629 & 1,629 & 828 & $50.8 \%$ \\
$\mathrm{e}^{* *}$ & 1,849 & 305 & 135 & $44.3 \%$ \\
total & $\mathbf{4 , 2 1 1}$ & $\mathbf{2 , 3 1 2}$ & $\mathbf{1 , 2 5 0}$ & $\mathbf{5 4 . 1 \%}$ \\
\hline
\end{tabular}

Notes: * Allowed Target: Only for the students in $10^{\text {th }}$ grade; ** Only for half of the classes in $12^{\text {th }}$ grade

Ethical considerations. Written consent was obtained from one of each participants' parents or guardians via Participation Consent Forms which were distributed to students along with the Research Information Sheet by teachers at each school in advance of data collection. Written consent from the students themselves was considered unnecessary, since it was made clear that participation in the study was voluntary and participants gave their verbal assent. The survey was administered in each school's computer rooms during computer classes. Seating arrangements were made so that no participants sat next to one another in order to assure their privacy while taking the survey. This protocol was approved

\footnotetext{
4 A study by Mahidol University et al. (2014) found the proportion of LGBT students to be $11.9 \%$.
} 
by both the Committee for Research on Human Subjects at Kyoto University (E1896) and the IPSR-Institutional Review Board at Mahidol University (No. 2013/1-1-23). In order to protect anonymity, no names or other specific personal information that could be used to identify the participants' identities were asked or recorded.

Data collection and measures. An online computer-assisted self-administered questionnaire was created as a tool for data collection, using Survey Monkey ${ }^{\circledR}$ (http://www.surveymonkey.com/), a provider of web-based surveys. The questionnaire was designed based on findings from the qualitative study and was pretested with 25 secondary school students who participated in the qualitative phase before the initiation of data collection. Measures used in this study included:

1) Demographics (9 items): Measures of age, religion, current grade, Grade Point Average (GPA), whether they are originally from Bangkok, whether they live with their parents, parents' marital status, whether they are working any part time job, and their daily allowance.

2) Sexuality (2 items): Participants were asked to choose their own sexual orientation and self-identified sexual identity from the following choices: gay, thud, katoey, bisexual, straight, questioning, or other. The Thai terms thud and katoey are discussed below.

3) Center for Epidemiologic Studies-Depression(CES-D) scale: Thai version (20 items): The CES-D scale was translated into Thai and tested by Worapongsathorn, Pundee, and Triamchaisri (1990). The cut-off point of the CES-D score in this study was set at 22 as suggested by a previous study of Thai CES-D scale by Trangkasombat et al. (1997) (sensitivity $=72 \%$, specificity $=85 \%$, Cronbach's coefficient alpha $=0.86$ ).

4) Self-Harm and Suicidality (3 items): Participants were asked if they have ever committed self-harm, considered suicide, or attempted suicide in the past semester (Yes or No).

5) Victimization (14 items): Experiences of victimization during the past semester by teachers, peers, parents, and strangers were asked, as well as sexual coercion, using 5 point scale response options (0:Never, 1:Less than once a week, 2:1-2 days a week, 3:3-4 days a week, 4:5-7 days a week). The question items were:

(1) Teachers or school staff said something or mocked how I act or talk to disdain or ridicule me.

(2) Teachers or school staff treated me differently, with prejudice.

(3) Teachers or school staff physically assaulted me, e.g. kicked, punched, hit me etc.

(4) Other students called me "fag", "gay", "gold-digger5", or other similar names.

(5) Other students said something or mocked how I act or talk to disdain or ridicule me.

(6) Other students treated me differently, with prejudice.

(7) Other students physically assaulted me, e.g. kicked, punched, hit, stomped me etc.

(8) Other students bullied me by forcibly taking my clothes off.

(9) My parents disdained or scolded me.

(10) My parents treated me differently, with prejudice.

\footnotetext{
5 The word "gold" in "gold-digger" is a euphemism for excrement. "Gold-digger" in the Thai context thus is a word used to ridicule sexual minority males, as it refers to sexual intercourse between men.
} 
(11) My parents physically assaulted me, e.g. slapped, kicked, punched, hit me etc.

(12) I felt that people were gossiping about me when I was out in public.

(13) Strangers yelled or made hurtful remarks towards me when I was out in public.

(14) Somebody forced, or tried to force me sexually.

Scores in each category of victimization (victimization by teachers, peers, parents, in public, and sexual coercion) were summed up, and categorized to four levels (Never/ Low/ Moderate/ High). Responses about sexual coercion were classified into "Never" or "At least once" in the past semester.

Data analysis. Statistical analyses were performed using IBM ${ }^{\circledR}$ SPSS ${ }^{\circledR}$ Statistics Desktop Version 21.0. Descriptive analysis was performed with all variables in order to identify distributions of the data. Consequently, bivariate associations between sexuality and other variables were identified. For depressive symptomatology, a previous study suggested a cut-off point for the Thai version at 22 (sensitivity $=72 \%$, specificity $=85 \%$ ), with a Cronbach's coefficient alpha of 0.86 (Trangkasombat et al., 1997). In the current study, Cronbach's coefficient alpha was 0.88. Participants who scored 22 or over on the CES-D scale were grouped as "High CES-D," suggesting a higher risk for depressive symptoms than those grouped as "Low CES-D", whose scores were below the cut-off point. It is important to note that, although CES-D scale can discriminate well between patients of clinical depression and general population, it is not a diagnostic tool and should not be used as one (Radloff, 1977). The group of participants who score above the cut-off point, hence, should be interpreted merely as a group with higher risk for depression, and the prevalence should not be interpreted as the prevalence of illness.

Adolescents who self-identified as gay $(\mathrm{n}=27)$, young $\operatorname{transgender}^{6}($ thud $)(\mathrm{n}=24)$, transgender (katoey) $(\mathrm{n}=18)$, or bisexual $(\mathrm{n}=27)$, were classified as being in the "sexual minority" group. "Questioning" participants $(n=53)$ were also included in the sexual minority group since there was no difference in their experiences of victimization, depressive symptomatology and other outcomes from other sexual minority students; this is consistent with findings from a previous study (Williams et al., 2005). Among participants who chose "Others" $(\mathrm{n}=35)$ without further specification, only those who answered that they are sexually attracted "only to men", "mostly to men, but have also felt sexually attracted to women at least once", "to both men and women", or "mostly to women, but have also felt sexually attracted to men at least once" in the sexual orientation question item were classified as being in the "sexual minority" group. Those who did not answer both

\footnotetext{
${ }^{6}$ Participants of the qualitative phase did differentiate between young transgender and transgender. For details,
} please refer to an article on the qualitative phase of this study by Sopitarchasak et al. (2015). 
questions or whose sexuality could not be identified through the method explained in this paragraph $(n=71)$ were excluded from this study.

\section{Results}

Detailed results of the qualitative study can be found in our earlier article (Sopitarchasak et al., 2015). The qualitative study was used to investigate the male adolescents' understanding of sexual identity and the types of victimization they experienced. Participants were aware of five male sexual identities, which were gay, young transgender (thud), transgender (katoey), bisexual, and straight. Although sexual orientation was an important part of how they differentiated straight and bisexual from the others, gender expression was also heavily drawn on in distinguishing between gay, young transgender, and transgender. Sexual minority adolescents reported experiencing victimization based on their gender/sexuality in three major environments: at home, at school and in public. At home, they experienced different levels of rejection from parents, ranging from verbal insults to physical assaults such as punching or slapping. At school, they encountered occasional bullying and name-calling by intolerant peers. They also reported some teachers insulting their same-sex attraction and treating them differently in a prejudiced manner. In public, insulting, name-calling, and gossiping from strangers were common. However, they also felt tolerance towards their gender/sexuality had been increasing in school and in public settings in recent years. On the other hand, they perceived more pressure against their gender/sexuality at home. As mentioned above, these qualitative findings were used to develop the quantitative questionnaire.

Overall 1,250 participants completed the quantitative survey. As seen in Table 2, nearly all (96.1\%) were 15 to 18 years old. Most (91.5\%) regarded themselves as Buddhists. About three quarters of the participants $(72.7 \%)$ were living with both of their parents, and $18.7 \%$ were living with only one of their parents. Among all participants, $81.8 \%$ could be identified as sexual non-minority and $12.5 \%$ as sexual minority, with $5.7 \%$ having missing or unidentifiable responses. There were no significant differences among socio-demographic variables between the non-minority and sexual minority groups, except for the means of Grade Point Average (GPA), where the mean GPA of sexual minority participants (3.38, SD was higher than that of the non-minority participants (Table 2). 
Table 2: Percentage distribution of participants' socio-demographic characteristics among non-minority and sexual minority youth

\begin{tabular}{|c|c|c|c|c|c|}
\hline \multicolumn{2}{|c|}{ Characteristics } & $\begin{array}{r}\text { Non-minority } \\
(\%)\end{array}$ & $\begin{array}{r}\text { Sexual minority } \\
(\%)\end{array}$ & $\begin{array}{r}\text { Total } \\
(\%)\end{array}$ & $p$ value* \\
\hline \multirow{4}{*}{ Age } & 15 or under & 16.4 & 09.6 & 15.5 & \\
\hline & 16 & 30.2 & 28.2 & 29.9 & \\
\hline & 17 & 32.1 & 37.2 & 32.7 & \\
\hline & 18 or over & 21.3 & 25.0 & 21.8 & 0.105 \\
\hline \multirow[t]{5}{*}{ School } & a & 7.3 & 5.1 & 7.0 & \\
\hline & $\mathrm{b}$ & 6.0 & 5.8 & 5.9 & \\
\hline & c & 9.6 & 10.9 & 9.8 & \\
\hline & d & 67.0 & 60.9 & 66.2 & \\
\hline & e & 10.2 & 17.3 & 11.1 & 0.086 \\
\hline \multirow[t]{2}{*}{ Religion } & Buddhism & 91.2 & 93.5 & 91.5 & \\
\hline & Others & 8.8 & 6.5 & 8.5 & 0.327 \\
\hline \multirow{3}{*}{ Current grade } & $10^{\text {th }}$ & 33.0 & 27.6 & 32.3 & \\
\hline & $11^{\text {th }}$ & 28.9 & 25.6 & 28.5 & \\
\hline & $12^{\text {th }}$ & 38.0 & 46.8 & 39.2 & 0.109 \\
\hline \multirow{2}{*}{\multicolumn{2}{|c|}{ Grade Point Average (S.D.) }} & 3.05 & 3.31 & 3.08 & 0.000 \\
\hline & & $(0.70)$ & $(0.72)$ & $(0.73)$ & \\
\hline \multirow[t]{2}{*}{ Born in Bangkok } & Yes & 78.5 & 80.1 & 78.7 & \\
\hline & No & 21.5 & 19.9 & 21.3 & 0.642 \\
\hline \multirow[t]{4}{*}{ Currently living with } & Both parents & 72.2 & 75.6 & 72.7 & \\
\hline & Only mother & 14.6 & 11.5 & 14.2 & \\
\hline & Only father & 4.2 & 6.4 & 4.5 & \\
\hline & of the parents & 9.0 & 6.4 & 8.7 & 0.308 \\
\hline \multirow[t]{3}{*}{ Parents' marital status } & Married & 75.8 & 75.0 & 75.7 & \\
\hline & Separated & 9.1 & 12.8 & 9.6 & \\
\hline & Divorced & 9.6 & 6.4 & 9.2 & \\
\hline Either or & are deceased & 5.6 & 5.8 & 5.6 & 0.325 \\
\hline \multirow[t]{5}{*}{ Part-time job } & Never & 67.6 & 65.4 & 67.3 & \\
\hline & Not anymore & 9.5 & 13.5 & 10.0 & \\
\hline & m time to time & 10.4 & 9.0 & 10.2 & \\
\hline & g school break & 7.6 & 5.1 & 7.3 & \\
\hline & Always & 4.9 & 7.1 & 5.2 & 0.300 \\
\hline
\end{tabular}

* For categorical variables, Chi-Square test was used to assess the differences among categories. For Grade Point Average, the only interval variable, t-test was conducted to compare the difference of means.

Overall 235 participants (19.9\%) scored 22 or higher (high CES-D) on the CES-D scale (indicating that they were more likely to be clinically depressed). Comparing the two sexuality/gender groups, the prevalence rate of having a high CES-D score was significantly higher in the sexual minority participants $(29.5 \%)$ than in the non-minority $(18.5 \%)$. The mean CES-D score among sexual minority adolescents was 17.6, whereas among non-minority participants the mean score was 15.1 (effect size $=0.32$ ). Overall, the Cronbach's coefficient alpha was 0.88 .

About $20 \%$ of the participants had engaged in self-harm in the past semester. However, there was no significant difference in the prevalence of self-harm between the two groups. 
Suicidality was significantly more common in the sexual minority group (Table 3). Nearly one in four $(23.2 \%)$ sexual minority participants reported having considered suicide while only $9.8 \%$ of non-minority participants had done so. Moreover, $10.3 \%$ of sexual minority participants had attempted suicide in the past semester, while only $2.9 \%$ among the non-minority group had done so.

Table 3: Bivariate analyses of depressive symptomatology, suicidality, and victimization among non-minority and sexual minority groups

\begin{tabular}{|c|c|c|c|c|c|c|}
\hline & & $\begin{array}{c}\text { Non-minority } \\
(\%) \\
(n=1,023)\end{array}$ & $\begin{array}{c}\text { Sexual minority } \\
\left(\begin{array}{c}\%) \\
(n=156)\end{array}\right.\end{array}$ & $\begin{array}{c}\text { Total } \\
(\%) \\
(n=1,179)\end{array}$ & $\underset{H}{p \text { value }}$ & OR $(95 \% \mathrm{CI})$ \\
\hline \multirow[t]{2}{*}{ Depression } & Low CES -D & 81.5 & 70.5 & 80.1 & & \\
\hline & High CES -D & 18.5 & 29.5 & 19.9 & 0.001 & $1.85(1.24-2.70)$ \\
\hline \multirow[t]{2}{*}{ Self -harm } & No & 79.6 & 80.6 & 79.8 & & \\
\hline & Yes & 20.4 & 19.4 & 20.2 & 0.769 & $0.94(0.61-1.44)$ \\
\hline \multirow[t]{2}{*}{ Suicide thought } & No & 90.2 & 76.8 & 188.4 & & \\
\hline & Yes & 9.8 & 23.2 & 11.6 & 0.000 & $2.79(1.82-4.27)$ \\
\hline \multirow[t]{2}{*}{ Suicide attempt } & No & 97.1 & 89.7 & 96.1 & & \\
\hline & Yes & 2.9 & 10.3 & 3.9 & 0.000 & $3.80(2.02-7.16)$ \\
\hline \multirow{4}{*}{$\begin{array}{l}\text { Victimization by } \\
\text { teachers }\end{array}$} & Never $(0)$ & 47.2 & 38.5 & 46.1 & & \\
\hline & Low $(1-3)$ & 41.3 & 44.9 & 41.7 & & $1.34(0.92-1.93)$ \\
\hline & Moderate (4 -6) & 10.2 & 11.5 & 10.3 & & $1.39(0.79-2.46)$ \\
\hline & High (7 -12) & 1.4 & 5.1 & 1.9 & 0.004 & 4.60 (1.85 -11.42) \\
\hline \multirow{4}{*}{$\begin{array}{l}\text { Victimization by } \\
\text { peers }\end{array}$} & Never $(0)$ & 46.9 & 23.1 & 43.8 & & \\
\hline & Low $(1-5)$ & 43.6 & 54.5 & 45.0 & & $2.54(1.69-3.83)$ \\
\hline & Moderate (6 -10) & 8.2 & 14.1 & 9.0 & & $3.49(1.96-6.23)$ \\
\hline & High (11 -20) & 1.3 & 8.3 & 2.2 & 0.000 & $13.33(5.76-30.89)$ \\
\hline \multirow{4}{*}{$\begin{array}{l}\text { Victimization by } \\
\text { parents }\end{array}$} & Never $(0)$ & 46.2 & 47.4 & 46.4 & & \\
\hline & Low $(1-3)$ & 43.3 & 37.2 & 42.5 & & $0.84(0.58-1.21)$ \\
\hline & Moderate (4 -6) & 8.4 & 11.5 & 8.8 & & $1.34(0.76-2.35)$ \\
\hline & High (7 -12) & 2.1 & 3.8 & 2.3 & 0.200 & $1.83(0.71-4.67)$ \\
\hline \multirow{4}{*}{$\begin{array}{l}\text { Victimization in } \\
\text { public }\end{array}$} & Never $(0)$ & 48.8 & 26.9 & 45.9 & & \\
\hline & Low $(1-2)$ & 40.7 & 44.2 & 41.1 & & $1.97(1.31-2.96)$ \\
\hline & Moderate (3-4) & 8.2 & 18.6 & 9.6 & & $4.10(2.42-6.95)$ \\
\hline & High (5 -8) & 2.3 & 10.3 & 3.4 & 0.000 & $7.92(3.91-16.06)$ \\
\hline \multirow[t]{2}{*}{ Sexual coercion } & Never $(0)$ & 93.6 & 80.1 & 91.9 & & \\
\hline & At least once (1-4) & 6.4 & 19.9 & 8.1 & 0.000 & $3.66(2.29-5.82)$ \\
\hline
\end{tabular}

\# Chi-Square test

Regardless of victimization category (victimization by peers, teachers, parents, or in public), approximately $10 \%$ of participants reported being victimized at a moderate or high level. For victimization by teachers, peers, or strangers, sexual minority participants were more likely to be victimized at a moderate or high level than their non-minority peers (Table 3). In addition, odds ratios of victimization by peers and by strangers increase as the level of victimization escalates (Table 3). The Mantel-Haenszel test for trend also suggested the trends were significant with $p$ value less than 0.001 . Although no significant difference was found between the two groups in their levels of victimization by parents, when the analyses were conducted for each item within the "victimization by parents" scale items, sexual 
minority participants were more likely to have been physically abused by their parents, with $3.2 \%$ reporting having been physically assaulted by parents 3-7 days per week in the past semester, compared to $0.6 \%$ among the non-minority participants (results not shown). Sexual coercion was relatively common; overall $8.1 \%$ of all participants indicated they had experienced this. Sexual minority participants were three times more likely to have been sexually abused at least once in the past semester, compared to the non-minority group (19.9\% vs. 6.4\%). Furthermore, higher levels of victimization in every category and sexual coercion were significantly associated with tendencies of depression, self-harm, suicide thoughts, and suicide attempts (results not shown).

\section{Discussion}

This study investigates the issue of disparity in mental well-being status and experiences of victimization between non-minority and sexual minority adolescents in Thailand. We decided to adopt a mixed methods design for this study, which allowed us to utilize findings from the qualitative study to develop the questionnaire used in the quantitative study. The prevalence of higher risk for depression, self-harm, suicidality, and experiences of victimization among the two sexuality groups were explored to investigate the differences among them. The results revealed that sexual minority adolescents were at higher risk for depression and suicidality, and had experienced victimization more heavily than their non-minority counterparts.

The total prevalence of High CES-D was 19.9\% in this study, consistent with the result (19\%) of a previous study regarding depressive symptoms among male secondary school students in Thailand (Trangkasombat \& Rujiradarporn, 2012). When comparing the two sexuality/gender groups, sexual minority participants were almost two times more likely to score over the cut-off point, suggesting a higher risk for clinical depression. This finding is also consistent with results from previous studies outside Thailand, indicating that sexual minority adolescents' mental well-being status in Thailand is also being compromised.

Previous research, including a meta-analytic study, have suggested a strong association between suicidality and being in a sexual minority (Fergusson et al., 2005; Garofalo et al., 1999; Marshal et al., 2011; Remafedi, French, Story, Resnick \& Blum, 1998; Russell \& Joyner, 2001). This was found to be consistent in our current study as well. Sexual minority participants in this study were almost four times more likely to have attempted, and almost three times more likely to have considered suicide than non-minority youth. Thus we suggest that interventions to prevent suicides among adolescents be focused especially on sexual minority adolescents. However, despite the substantial difference in suicidality 
between the two groups, it is of interest that there was no significant differences in the two groups regarding self-harm. Further studies, especially qualitative inquiries, are needed to investigate the reasons behind this phenomenon.

As proposed by Meyer (2003), such compromised mental health outcomes (depression and suicidality) among sexual minority groups may be caused by distal (prejudice events) and proximal (expectation of rejection, concealment, internalized homophobia) minority stress processes. Evidently, sexual minority participants were more likely to be victimized especially by their peers and strangers in public, with significantly higher odds ratios at every level (low, moderate, and high). They were also more likely to be victimized by teachers and physically abused by their parents. These findings are against the common perception that sexual minorities in Thailand are well and widely accepted. Other studies by international agencies also confirm that sexual minorities in Thailand still encounters prejudice, which are rooted from a lack of understanding about diverse sexualities (Suriyasarn, 2014; UNDP \& USAID, 2014). The report by the UNDP and USAID (2014) also argued that striving for family acceptance is the biggest issue for sexual minorities in Thailand.

The prevalence of sexual coercion found in this study $(8.1 \%)$ was slightly higher than that of $6.5 \%$ in northern Thailand as reported by Manopaiboon et al. (2003). Sexual minority participants were over three times more likely to have been sexually coerced. The finding was consistent with the previous study by Manopaiboon et al. (2003), which reported the odds ratio of 7.3 (95\% CI= 4.0-13.3) for homosexual/bisexual self-identification as a factor associated with sexual coercion. The higher tendency of sexual minority adolescents being sexually coerced raises concern over the higher risks for HIV and other STDs, as condoms are reportedly used less than half the time when sexual coercion occurs (Guadamuz et al., 2011; Manopaiboon et al., 2003). In addition, as many studies have shown, sexual coercion during adolescence is significantly associated with subsequent HIV risk-taking behaviors (Bensley, Van Eenwyk \& Simmons, 2000; Brennan, Hellerstedt, Ross \& Welles, 2007; Holmes \& Slap, 1998; Mimiaga et al., 2009; O'Leary, Purcell, Remien \& Gomez, 2003; Senn, Carey, Vanable, Coury-Doniger \& Urban, 2006)

According to Meyer (2003), such experiences of victimization and sexual coercion are distal minority stressors which can negatively impact mental well-being. In this study, we found a significant association between victimizations/sexual coercion and adverse mental well-being measures. Arguably, it is likely that the greater frequency of victimization and sexual coercion results in worsened mental well-being among the sexual minority participants. Although the results support Meyer's minority stress model, the cross-sectional 
nature of the current study limits the ability to infer causal relationships among the variables. Nonetheless, a previous longitudinal study has suggested that higher depressive symptoms and suicidality among sexual minorities are significantly mediated through victimization specific to the sexual minority (Burton et al., 2013).

Although the results from the quantitative study indicated no significant difference in victimization by parents, findings from the qualitative study showed that sexual minority participants felt more pressure at home. Many sexual minority participants during the qualitative study had not yet come out to their parents at the time. Some of those who had not come out to parents mentioned having to be highly careful with their actions and personalities any time they were with parents, in order to hide their sexual identity. Even some of the participants who were already open about their sexual identity to their families mentioned feeling guilty for having disappointed their parents because of their sexual identity. In another study, de Lind van Wijngaarden \& Ojanen (2016) have found that gay identity was considered a defect by gay participants themselves who also believed that they needed to make up for such defect by being good persons for their families. According to Meyer's minority stress process, these kinds of stigma concerns, where sexual minority adolescents feel that their sexuality is a defect, are proximal minority stresses which can possibly have adverse effects on mental well-being (Meyer, 2003).

Another issue of interest is the significant difference in the mean GPA between the two sexuality groups. Overall, sexual minority participants' GPA was higher than that of the non-minority. This finding was inconsistent with previous studies abroad which suggested the opposite (Pearson, Muller \& Wilkinson, 2007; Rostosky, Owens, Zimmerman \& Riggle, 2003). This may possibly be explained by findings from the qualitative phase, where some of the sexual minority participants regarded they had to study hard and do better in order to compensate for their sexuality and not be disrespected. This phenomenon also goes in line with the results of studies by Suriyasarn (2014) and de Lind van Wijngaarden \& Ojanen (2016) which found that LGBT and especially transgender persons in Thailand believed that they must work harder than the non-minority persons to earn respect from people around them.

According to Meyer (2003), coping and social support can possibly help alleviate the compromised mental well-being caused by minority stresses. Schools seem to be the most suitable place for supporting programs since adolescents spend most of their time at school. Gay-straight alliances or similar organizations, an inclusive curriculum that includes positive representations of LGBT people, supportive educators, and comprehensive bullying/harassment policies or laws, are recommended by Gay, Lesbian $\mathcal{E}$ Straight Education 
Network (GLSEN) as solutions to provide safe environments for sexual minority students (Kosciw, Greytak, Bartkiewicz, Boesen \& Palmer, 2012).

In Thailand, although the Child Protection Act was enacted in 2003, it does not explicitly address bullying. The law's vision is limited to "torture" which it defines as:

...any commission or omission of acts which cause the deprivation of freedom of, or mental or physical harm to, a child; sexual abuses committed against a child; inducement of a child to act or behave in a manner which is likely to be mentally or physically harmful to the child, unlawful or immoral, regardless of the child's consent. (Child Protection Act, B.E. 2546, 2003)

Overall, the law seems to be written with torture as an act conducted by adults to children. As a result, further interpretation is needed if one wants to apply the law to cases of bullying by peers, which is deemed difficult since verbal or emotional abuse especially by peers is not usually perceived as torture and often overlooked. And although the Ministry of Education has established student protection centers in 2012 to holistically assist and help students (Ministry of Education, 2012), currently there is no evidence regarding the mechanism's efficiency in addressing bullying. Furthermore, until now there has not been a formal action taken by professional associations of Thai mental health professions to tackle the issue of mental well-being for sexual minorities (Ojanen, Ratanashevorn \& Boonkerd, 2016).

As for developing an inclusive curriculum, comprehensive sexuality education is required to be taught at school by the Prevention and Remedial Measures for Adolescent Pregnancy Act, B.E. 2559 (Royal Thai Government, 2016). Although the curriculum does include topics regarding sexual minorities, such topics are covered less than they should (UNDP \& USAID, 2014).

On the community level, especially within school communities, gay-straight alliances or similar structures do not exist in Thailand. Nor do secondary schools in Thailand have concrete policies to address bullying problems, especially when a bullying event is based on perceived sexual minority status. When measures against bullying exist, they tend to be ad hoc to solve certain bullying cases that emerged, while lacking systematic procedures (Mahidol University et al., 2014).

In fact, many participants from the qualitative phase reported being discriminated against due to their sexuality by teachers, and some also mentioned being prohibited from applying for a scholarship due to their sexuality. Since we found from the qualitative study that sexual minority participants felt more pressure at home, we suggest supporting programs also involve parents or guardians into interventions as well. 
There are several limitations to the current study. Since the participants in this study were male secondary school students in Bangkok, Thailand, generalization to other populations in other contexts is not recommended. The cross-sectional nature of the study also limits the ability to make causal inferences between the variables of interest. However, although participating schools were not recruited randomly, and there were schools which refused to participate, the refusals were due to limitation in their class schedules and were considered not to systematically bias the results. Despite several limitations, the nature of this study, which included male secondary school students in the general population regardless of their gender expression and sexuality, allowed us to identify the proportion of male sexual minority adolescents. However, because of the low numbers of participants with specific identities, subgroup analyses within the sexual minority group could not be properly conducted. Future studies that recruit more sexual minority adolescents is needed in order to further investigate risk factors related to adverse metal well-being within the sexual minority population.

\section{References}

Almeida, J., Johnson, R. M., Corliss, H. L., Molnar, B. E., \& Azrael, D. (2009). Emotional distress among LGBT youth: The influence of perceived discrimination based on sexual orientation. Journal of Youth and Adolescence, 38, 1001-1014. doi: 10.1007/s10964-009-9397-9

Bensley, L. S., Van Eenwyk, J., \& Simmons, K. W. (2000). Self-reported childhood sexual and physical abuse and adult HIV-risk behaviors and heavy drinking. American Journal of Preventive Medicine, 18(2), 151-8. doi: 10.1016/S0749-3797(99)00084-7

Birkett, M., Espelage, D. L., \& Koenig, B. (2009). LGB and questioning students in schools: the moderating effects of homophobic bullying and school climate on negative outcomes. Journal of Youth and Adolescence, 38(7), 989-1000. doi: 10.1007/s10964-008-9389-1

Boonkerd, S., \& Rungreangkulkij, S. (2014). ความชุกของภาวะซึมเศร้า การรับรู้ปัญหา และรูปแบบการเผชิญปัญหา ของกลุ่มหญิงรักหญิงในภาคตะวันออกเฉียงเหนือ [Prevalence of depression, problem recognition and coping strategies among lesbians, in northeastern Thailand]. Journal of Nursing Science E Health, 37(2), 92-101.

Brennan, D. J., Hellerstedt, W. L., Ross, M. W., \& Welles, S. L. (2007). History of childhood sexual abuse and HIV risk behaviors in homosexual and bisexual men. American Journal of Public Health, 97(6), 1107-12. doi: 10.2105/AJPH.2005.071423

Burton, C. M., Marshal, M. P., Chisolm, D. J., Sucato, G. S., \& Friedman, M. S. (2013). Sexual minority-related victimization as a mediator of mental health disparities in sexual minority youth: a longitudinal analysis. Journal of Youth and Adolescence, 42(3), 394-402. doi: $\underline{10.1007 / \mathrm{s} 10964-012-9901-5}$

Child Protection Act, B.E. 2546 (2003). Thailand.

Chow, S.-C., Wang, H., \& Shao, J. (2007). Sample Size Calculations in Clinical Research (2nd ed.). CRC press.

Clements-Nolle, K., Marx, R., \& Katz, M. (2006). Attempted suicide among transgender persons. Journal of Homosexuality, (February 2013), 37-41.

Consolacion, T., Russell, S., \& Sue, S. (2004). Sex, race/ethnicity, and romantic attractions: multiple minority status adolescents and mental health. Cultural Diversity and Ethnic Minority Psychology, 
(1995). doi: 10.1037/1099-9809.10.3.200.

De Lind van Wijngaarden, J. W., \& Ojanen, T. T. (2016). Identity management and sense of belonging to gay community among young rural Thai same-sex attracted men: implications for HIV prevention and treatment. Culture, Health \& Sexuality, 18(4), 377-390. doi: $\underline{10.1080 / 13691058.2015 .1087595}$

Diamant, A. L., \& Wold, C. (2003). Sexual orientation and variation in physical and mental health status among women. Journal of Women's Health (2002), 12(1), 41-9. doi: $\underline{10.1089 / 154099903321154130}$

Diaz, R., Ayala, G., \& Bein, E. (2001). The impact of homophobia, poverty, and racism on the mental health of gay and bisexual Latino men: findings from 3 US cities. American Journal of Public Health, 91(6), 927-32.

DiStefano, A. S. (2008). Suicidality and self-harm among sexual minorities in Japan. Qualitative Health Research, 18(10), 1429-41. doi: $10.1177 / 1049732308322605$

Fergusson, D. M., Horwood, L. J., Ridder, E. M., \& Beautrais, A. L. (2005). Sexual orientation and mental health in a birth cohort of young adults. Psychological Medicine, 35(7), 971-981. doi: $\underline{10.1017 / S 0033291704004222}$

Fitzpatrick, K. K., Euton, S. J., Jones, J. N., \& Schmidt, N. B. (2005). Gender role, sexual orientation and suicide risk. Journal of Affective Disorders, 87(1), 35-42. doi: 10.1016/i.jad.2005.02.020

Galliher, R. V., Rostosky, S. S., \& Hughes, H. K. (2004). School belonging, self-esteem, and depressive symptoms in adolescents: An examination of sex, sexual attraction status, and urbanicity. Journal of Youth and Adolescence, 33(3), 235-245. doi: 10.1023/B:JOYO.0000025322.11510.9d

Garofalo, R., Wolf, R. C., Wissow, L. S., Woods, E. R., \& Goodman, E. (1999). Sexual orientation and risk of suicide attempts among a representative sample of youth. Archives of Pediatrics $\mathcal{E}$ Adolescent Medicine, 153(5), 487-93. doi: 10.1001/archpedi.153.5.487.

Guadamuz, T. E., Wimonsate, W., Varangrat, A., Phanuphak, P., Jommaroeng, R., Mock, P. a., ... Van Griensven, F. (2011). Correlates of forced sex among populations of men who have sex with men in Thailand. Archives of Sexual Behavior, 40(2), 259-266. doi: 10.1007/s10508-009-9557-8

Holmes, W., \& Slap, G. (1998). Sexual abuse of boys. Journal of the American Medical Association, 18(1), 10-6. doi: $10.1111 / j .1744-6171.2005 .00005 . x$

Kessler, R. C., Berglund, P., Demler, O., Jin, R., Merikangas, K. R., \& Walters, E. E. (2005). Lifetime prevalence and age-of-onset distributions of DSM-IV disorders in the National Comorbidity Survey Replication. Archives of General Psychiatry, 62(June), 593-602. doi: 10.1001/archpsyc.62.6.593

King, M., McKeown, E., Warner, J., Ramsay, A., Johnson, K., Cort, C., ... Davidson, O. (2013). Mental health and quality of life of gay men and lesbians in England and Wales: Controlled, cross-sectional study. The British Journal of Psychiatry, 183(6), 552-558. doi: 10.1192/03-207

Kosciw, J. G., Greytak, E. A., Bartkiewicz, M. J., Boesen, M. J., \& Palmer, N. A. (2012). The 2011 National School Climate Survey. New York: Gay, Lesbian \& Straight Education Network.

Mahidol University, Plan International, \& UNESCO. (2014). Bullying targeting secondary school students who are or are perceived to be transgender or same-sex attracted: Types, prevalence, impact, motivation and preventive measures in 5 provinces of Thailand. Bangkok.

Manopaiboon, C., Kilmarx, P. H., Limpakarnjanarat, K., Jenkins, R. A., Chaikummao, S., Supawitkul, S., \& van Griensven, F. (2003). Sexual coercion among adolescents in northern Thailand: prevalence and associated factors. The Southeast Asian Journal of Tropical Medicine and Public Health, 34(2), 447-57.

Marshal, M. P., Dietz, L. J., Friedman, M. S., Stall, R., Smith, H. A., McGinley, J., .. Brent, D. a. (2011). Suicidality and depression disparities between sexual minority and heterosexual youth: a meta-analytic review. Journal of Adolescent Health : Official Pub, 49(2), 115-23. doi: 10.1016/j.jadohealth.2011.02.005 
McEwan, K., Waddell, C., Barker, J., \& Kirby, M. (2007). Bringing children's mental health "out of the shadows." Canadian Medical Association Journal, 176(May 2006), 471-472.

Meyer, I. H. (2003). Prejudice, social stress, and mental health in lesbian, gay, and bisexual populations: conceptual issues and research evidence. Psychological Bulletin, 129(5), 674-679. doi: $\underline{10.1037 / 0033-2909.129 .5 .674}$

Mimiaga, M. J., Noonan, E., Donnell, D., Safren, S. A., Koenen, K. C., Gortmaker, S., ... Mayer, K. H. (2009). Childhood sexual abuse is highly associated with HIV risk-taking behavior and infection among MSM in the EXPLORE study. Journal of Acquired Immune Deficiency Syndromes, 51(3), 340-348. doi: 10.1097/QAI.0b013e3181a24b38.Childhood

Ministry of Education. (2012). ประกาศสำนักงานคณะกรรมการศึกษาขั้นพื้นฐาน เรื่องแบ่งส่วนราชการสำนักงาน คณะกรรมการศึกษาขั้นพื้นฐาน (เป็นการภายใน) [Office of the Basic Education Comission's Legal Notice: Segmenation of the Basic Education Comission].

Ministry of Education. (2016). Number of Students in Schools Classified by Province, Grade, and Gender in 2015. Bangkok.

Ojanen, T. T., Ratanashevorn, R., \& Boonkerd, S. (2016). Gaps in responses to LGBT issues in Thailand: Mental health research, services, and policies. Psychology of Sexualities Review, 7(1), 41-59.

O'Leary, A., Purcell, D., Remien, R. H., \& Gomez, C. (2003). Childhood sexual abuse and sexual transmission risk behaviour among HIV-positive men who have sex with men. AIDS Care, 15(1), 17-26. doi: $10.1080 / 0954012021000039725$

Pearson, J., Muller, C., \& Wilkinson, L. (2007). Adolescent same-sex attraction and academic outcomes: The role of school attachment and engagement. Social Problems, 54(4), 523-542. doi: 10.1525/sp.2007.54.4.523.Adolescent

Radloff, L. S. (1977). The CES-D scale: A self-report depression scale for research in the general population. Applied Psychological Measurement, 1(3), 385-401. doi: 10.1177/014662167700100306

Remafedi, G., Farrow, J. A., \& Deisher, R. W. (1991). Risk Factors for Attempted Suicide in Gay and Bisexual Youth. Pediatrics, 87(6), 869-75.

Remafedi, G., French, S., Story, M., Resnick, M. D., \& Blum, R. (1998). The relationship between suicide risk and sexual orientation: results of a population-based study. American Journal of Public Health, 88(1), 57-60.

Rostosky, S. S., Owens, G. P., Zimmerman, R. S., \& Riggle, E. D. . (2003). Associations among sexual attraction status, school belonging, and alcohol and marijuana use in rural high school students. Journal of Adolescence, 26(6), 741-751. doi: 10.1016/j.adolescence.2003.09.002

Royal Thai Government. พระราชบัญญัติการตั้งครรภ์ในวัยรุ่นปี พ.ศ. 2559 [Prevention and Remedial Measures for Adolescent Pregnancy Act, B.E. 2559] (2016).

Russell, S. T., \& Joyner, K. (2001). Adolescent sexual orientation and suicide risk: evidence from a national study. American Journal of Public Health, 91(8), 1276-81.

Senn, T. E., Carey, M. P., Vanable, P. A., Coury-Doniger, P., \& Urban, M. A. (2006). Childhood sexual abuse and sexual risk behavior among men and women attending a sexually transmitted disease clinic. Journal of Consulting and Clinical Psychology, 74(4), 720-731. doi: 10.1037/0022-006X.74.4.720

Sopitarchasak, S., Samakkeekarom, R., Techasrivichien, T., Suguimoto, S. P., Tharawan, K., Kihara, M., \& Ono-Kihara, M. (2015). Victimization against non-heterosexual male adolescents in bangkok: A qualitative study. Social Science Asia, 1(4), 61-76.

Suriyasarn, B. (2014). Gender identity and sexual orientation in Thailand. Bangkok: International Labor Organization.

Trangkasombat, U., Larpboonsarp, V., \& Havanond, P. (1997). การใช้ CES-D ในการคัดกรอง ภาวะซึมเศร้าใน วัยรุ่น [CES-D as a screen for depression in adolescents]. Journal of the Psychiatric Association of Thailand, 42(1), 2-13. 
Trangkasombat, U., \& Rujiradarporn, N. (2012). Gender differences in depressive symptoms in Thai adolescents, 6(5), 737-745. doi: 10.5372/1905-7415.0605.115

UNDP, \& USAID. (2014). Being LGBT in Asia: Thailand Country Report. Bangkok.

Van Griensven, F., Kilmarx, P. H., Jeeyapant, S., Manopaiboon, C., Korattana, S., Jenkins, R. a, ... Mastro, T. D. (2004). The prevalence of bisexual and homosexual orientation and related health risks among adolescents in northern Thailand. Archives of Sexual Behavior, 33(2), 137-47.

Warner, J., McKeown, E., Griffin, M., Johnson, K., Ramsay, A., Cort, C., \& King, M. (2004). Rates and predictors of mental illness in gay men, lesbians and bisexual men and women: Results from a survey based in England and Wales. The British Journal of Psychiatry: The Journal of Mental Science, 185, 479-85. doi: 10.1192/bjp.185.6.479

Williams, T., Connolly, J., Pepler, D., \& Craig, W. (2005). Peer victimization, social support, and psychosocial adjustment of sexual minority adolescents. Journal of Youth and Adolescence, 34(5), 471-482. doi: $10.1007 /$ s10964-005-7264-x

Worapongsathorn, T., Pundee, W., \& Triamchaisri, S. (1990). คุณลักษณะความตรงของแบบสอบวัดความ ซึมเศร้า CES-D [Reliability and validity of CES-D scale]. Journal of Clinical Psychology, 21(2), 2545.

Yadegarfard, M., Meinhold-Bergmann, M. E., \& Ho, R. (2014). Family rejection, social isolation, and loneliness as predictors of negative health outcomes (depression, suicidal ideation, and sexual risk behaviour) among Thai male-tofemale transgender adolescents. Journal of LGBT Youth, 11, 347-363. 